\title{
Special aluminum piston deburring machine tool structure optimization design
}

\author{
Yuncai XIA
}

Department of Mechanical Engineering,Dalian Vocational Technical College,Dalian,Liaoning, 116037, China

laoliu2345@163.com

Keywords: Aluminum piston, Deburring, Drum Wheel, Slot wheel, Dividing movement

\begin{abstract}
In order to solve the problem of aluminum piston deburring, in the special deburring machine adopts the drum wheel unit as a clamp, slot wheel mechanism as intermittent mechanism, by the brush to remove burrs, through the literature material law, expert interview method, calculation analysis and other research methods, demonstrates the deburring machine structure rationality, the reliability of the work, the uniform deburring machine tool, a thorough conclusion.
\end{abstract}

\section{Introduction}

Aluminum piston is the part that be designed to hold the pressure caused by gas explosion in the cylinder, they are connected with rod and crankshaft and make it rotation. They are made in mass production. [1] [3]Due to the raw material is from casting, it will remain to be deburred after finish machining. The burr can be soft and hardly to be removed, so this article is focus on design a machine particularly for deburring and smoothing the surface of Aluminum piston. The basic function requirements for double side deburring machine are as follows.

1. The machine must be high efficient to remove the burr and smooth the surface.

2. The machine must have reliable dust cleaning device when working.

3. The machine should be flexibly operated without interference, loose and noise.

Main challenge are as follows.

1. The overall design.

2. Muti-spindle assemble design.

3. Intermittent mechanism design.

4. Main component design.

\section{The overall design plan of the machine tool}

Overall design include general planning making such as R\&D, technical Analysis and Machine layout.Main technical parameters planning such as dimension, motion parameter and dynamic parameter.

The basis of the machine tool overall design. The design plan is based on work pieces, like product, achievements of new technology[1] [2], working condition and manufacturing method.

1. Working accuracy target: Remove the burr and work functioning.

2. Automaticity: semi-automatic Design, use Drum wheel as fixture, manually upload the workpiece and unloading with a fork.

3. Operational reliability, Shield cover design to protect the safety during operation.

4. Style \& Color: Compact Design with Green powdering sheet metal which will ensure a delight mood during the work. The detail drawing is as follow. 


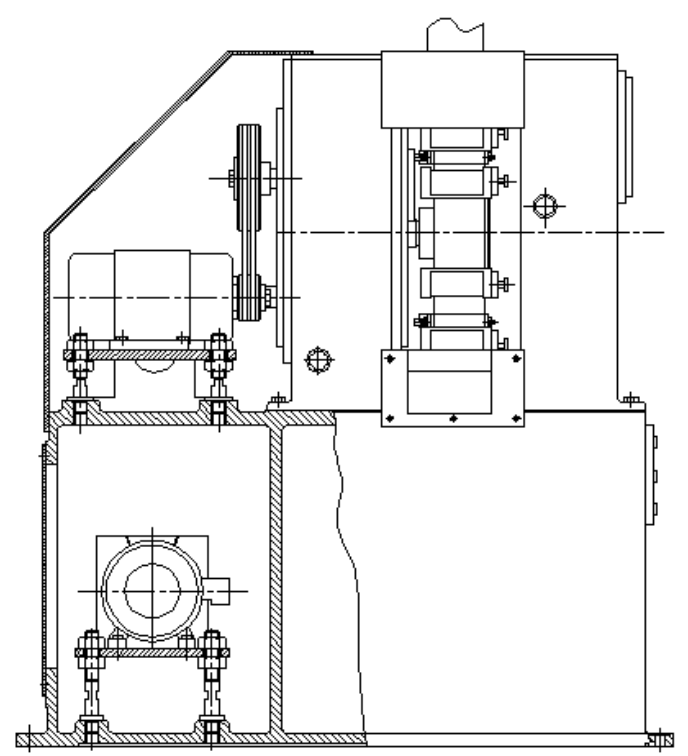

Fig.1 Overall structure of machine tool

Machine Tool Motion Design.The aluminum piston is deburred by 8 spinning brushes (mounted inside 2 spindle Boxes) and intermittent motion of drum wheel shaft.

Machine Tool Layout Design.The machine is composed of four units which are bed, base (mounted with electrical device), left muti-axis Box and right muti-axis Box. A special fixture for clamping the work piece is assembled in the main spindle box and it can spin vertically. [3] [6]At the end of the shaft is bolted with 8 brush units. Operation button and vent-pipe are set on the proper place on the machine.

1.Motion distribution. When Machine operation process method is determined, the relative motion between the workpiece and brushes is determined as well. [1] [2]But the relative motion can be assigned to the brush, can also can be assigned to the workpiece, or jointly by brush and workpiece. So it is decided by many factors.

First simplify the transmission and structure. Under the same conditions, by reducing the weight, the motor need less output power and size to drive the machine. [3] [5]So from the point of view to simplify the transmission, it is reasonable to distribute motion to less weight part as the drive component. The machine adopts two kinds of distribution of movement, one motion is a high speed 8 brushes rotary motion; Another motion is from dividing mechanism driving drum shaft fixture do intermittent movement.

Secondly is to increase machining precision. Compared with traditional manual deburring method, the quality only guaranteed by the skill workers at low efficiency and can differ from one another. [3] [5]The deburring machine, which is assembled by 8 brush units and drum wheel fixture moving forward and backward, can operate at high speed.

2.Transmission application.The traditional transmission of the machine is the combination of mechanical drive, hydraulic transmission, pneumatic, electrical, and other forms, as well as the synthesis of the situation. And it should fulfill the below requirements.

Firstly is to meet motion requirements. Some cases, the machine require a simple movement or composite one. Some cases, the machine require a straight movement or spinning movement or following other tracks. [5] [7] Some cases, the machine require changing speed and direction or brake.

Secondly is to meet motility requirements like machining operating speed, power, transmission force, and operation stroke. Ensure the transmission accuracy, positioning accuracy and movement smoothness.

Thirdly is to meet economical requirements like low-transmission equipment cost, low-manufacturing cost and low-maintenance cost level.

This machine adopts rotary movement as mechanical transmission with gear mechanism system for stepped speed changing. It works reliable, general manufacturing standard, and is widely used in 
machine tools.

\section{Mechanical Transmission Scheme Design}

In order to deburr the workpiece accurately and efficiently, the machine adopts drum wheels as its fixture and can loading 6 aluminum pistons at one time. For completely removing the burr, the machine adopt double side deburring using the slot wheel mechanism. [9] [10] When the roller on the arm rod goes into the slot, the slot wheel mechanism will turn oppositely. When the roller on the arm rod goes out of the slot, the slot wheel mechanism will stop and lock up. When arm rod turns a round, the slot wheel mechanism will do a step motion and the drum wheel will do intermittent movement. The detail drawing is as follow.
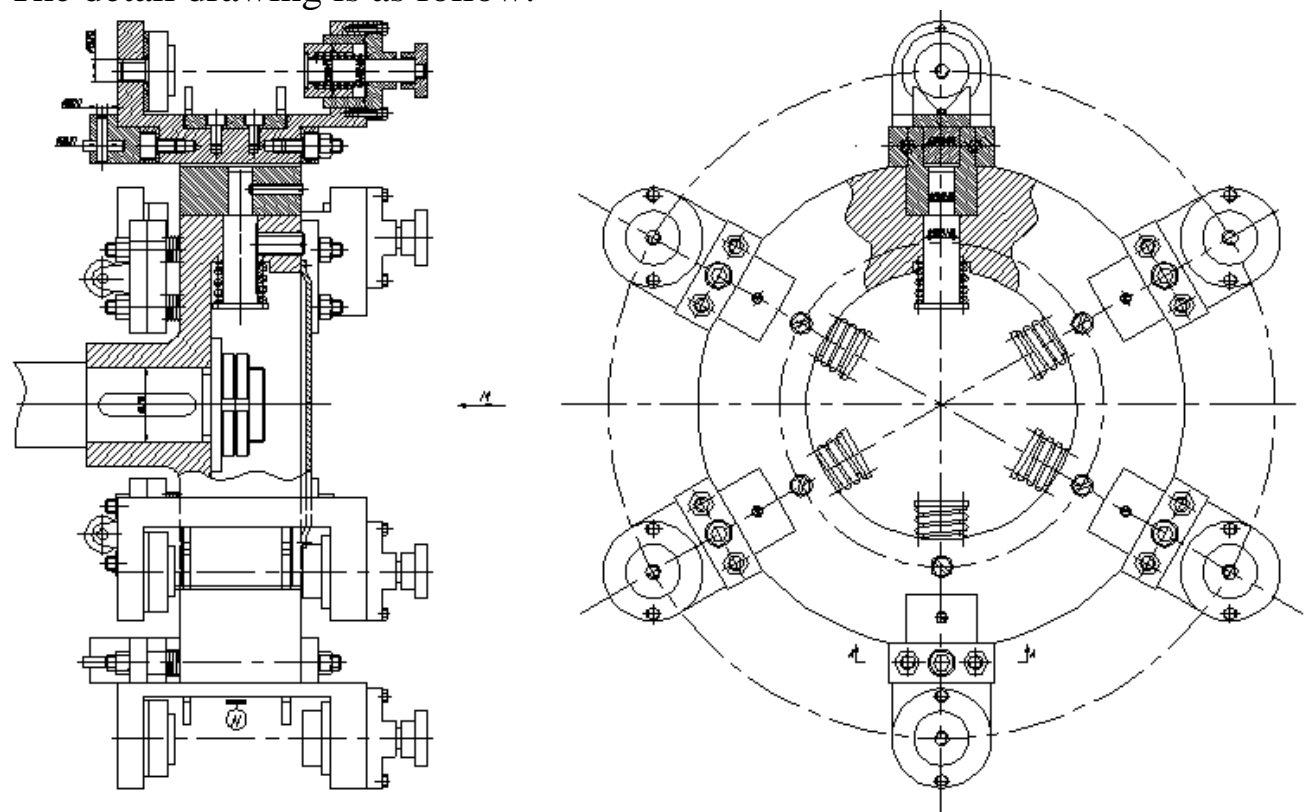

Fig.2 Drum Wheel Device sketch map

Due to the gear transmission is a rotary transmission, so other mechanisms are to rely on the chain to obtain power, its execution parts should be designed as a rotary movement, and on the basis of structure design.

\section{Driving plan design}

Original moving parts and the connecting way of reduction gear machine tool mainly drive belt, and belt transmission is mainly cooperate with two pulleys do rotary motion, thus the design of driving mechanism should be able to take other forms can be converted into torque work is done.

Based on past design experience, the motor selection, and other hydraulic, pneumatic, etc. are not appropriate. [8] And because of the requirement in the design of belt transmission speed is not high, we can design a deceleration device to meet the requirements of speed.

\section{Component Design}

Shafts Design. The shafts on the machine are for brushes and gears assembly. On the machine, there are 4 shafts for assemble the brushes, each two shafts are located with $30^{\circ}$ angle. Under the action of slot wheel mechanism, the drum wheel will turn $30^{\circ}$ angle as the arm makes a full revolution. So the aluminum piston is deburred. [7] [8]The raw material of shaft is 45\# carbon steel. It meets the strength requirements and very economical to use. And 6 shafts installed brush transmission between them adopt gear matching, ratio of 1:1, ensure the installation of six brush shafts turning at the same speed, working synchronously. At the same time, bearing houses with bearing inside are bolted. Despite of working load calculation when designing the shaft, we also take consider of other requirements like component assembly, heat-treatment, and maintenance etc. 
If the shaft is heavy duty shaft, we must also need to consider of raw material forging and nondestructive inspection. The detail drawing is as follow.

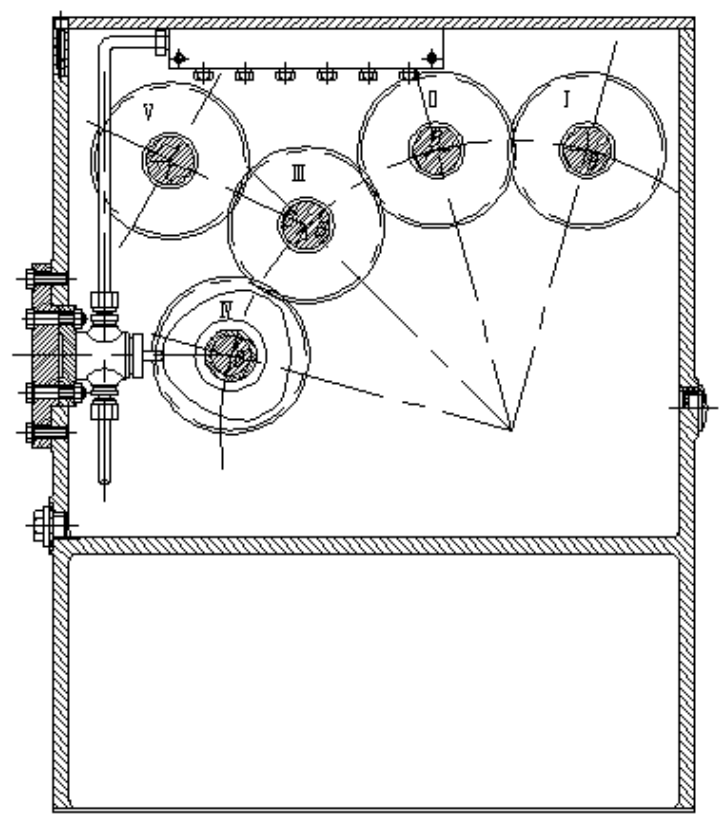

Fig.3Spindle box structure diagram

Bearing unit Design. The machine use standard deep groove ball bearing and following GB-Standard. So there are only two issues for choose the right bearing the dimension and the composite structure.

Bearing choosing should consider of and calculate the type, precision, assembly mating, supporting form. First choose the bearing structure type according to working condition. [7] Second choose bearing type and precision. Third choose the model of bearing. And last check the load bearing capacity and maximum rotating speed. These jobs can just normally follow the bearing manual.

Gear mechanism is widely used to pass any motion space and power between the two shafts, is one of the earliest applications of the transmission mechanism in history, Compared with other forms of transmission, it has the following advantages:

1.Ensures constant transmission ratio;

2.The applied load and velocity distribution are very wide.Transmission of power can be from very small to a few million kilowatts, The peripheral speed is up to $150 \mathrm{~m} / \mathrm{s}$

3.Compact structure

4.High efficiency, the general efficiencyis is $\eta=0.94 \square 0.99$

5.Work reliably and long life

In recent years, due to the rapid development of gear manufacturing technology, the constant improvement of the machining accuracy expands the application range of the gear. Therefore, the importance of the gear in the machinery manufacturing is more significant.

\section{Conclusion}

After finish above design analysis and calculation, the machine now can be started running. The drum wheel is driven by V-shape belt and spinning around, at the same time, another 3 shafts are driven by 3 engaging planetary gears. These 4 shafts ends are bolt-mounted with brushes driven through a reducer drive slot wheel mechanism, dividing motion between slot wheel mechanism and install fixture axis by a pair of gear transmission, drive the drum wheel do intermittent rotary motion in order to finish deburring for aluminum piston. 


\section{Acknowledgement}

This work was supported by Dalian Vocational \& Technical College,we are indebted to the support and encouragements received from the staff and colleagues of the school of computer engineering.

\section{References}

[1] Harbin Institute of Technology. Design and manufacture of special machine tool.Heilongjiang: Heilongjiang people's publishing house, 1979.12

[2] Shenyang heavy machinery factory for selection of machinery industry technical innovation technical transformation. Simple and efficient special machine tool. Beijing: China Machine Press, 1974, 2

[3] Beijing Mechanical Engineering Society. Modern manufacturing engineering. Beijing: China Machinery Engineering Society Process Management Professional Committee.2001.1

[4] Xu Hongben. Machine tool fixture design handbook. Liaoning: Liaoning science and Technology Press.2004.1

[5] "Mechanical Design Manual" writing group. Machine Design Manual Volume III. China Machine Press,1986,12

[6] Wu Zongze. Mechanical Design Manual I. Beijing: China Machine Press,2002

[7] Wu Zongze. Mechanical Design Manual 2. Beijing: China Machine Press,2002

[8] China Mechanical Engineering Society. China Mechanical Design Canon. Jiangxi :Jiangxi science and Technology Press,2002

[9] Cheng Daxian. Mechanical design drawings. Beijing: Chemical Industry Press,2000

[10] Wu Zongze. Design Handbook for mechanical components. China Machine Press,2004 